06

\title{
Исследование стабильности электрических свойств восстановленных кристаллов $\mathrm{LiNbO}_{3}$
}

\author{
() А.В. Яценко, ${ }^{1}$ А.С. Притуленко, ${ }^{1}$ С.В. Ягупов, ${ }^{1}$ Д.Ю. Сугак, ${ }^{2,3}$ И.М. Сольский ${ }^{3}$ \\ ${ }^{1}$ Крымский федеральный университет им. В.И. Вернадского, \\ 295007 Симферополь, Россия \\ ${ }^{2}$ Национальный университет „Львовская политехника“, \\ 79013 Львов, Украина \\ ${ }^{3}$ Научно-производственное предприятие „Карат“, \\ 79000 Львов, Украина \\ e-mail: lab2@crimea.edu
}

(Поступило в Редакцию 11 июля 2016 г.)

Методом импедансной спектроскопии исследована нестабильность электрических свойств монокристаллов ниобата лития конгруэнтного состава, прошедших восстановительную термохимическую обработку. Показано, что при последующих нагревах восстановленных образцов ниобата лития в сухом воздухе до $380 \mathrm{~K}$ и более происходит прогрессирующее увеличение их электрического сопротивления, что связано с оксидизацией приповерхностных слоев кристалла.

DOI: 10.21883/JTF.2017.07.44676.1984

\section{Введение}

Кристаллы ниобата лития $\mathrm{LiNbO}_{3}$ (НЛ) являются сегнетоэлектрическим материалом, который нашел широкое применение в электрооптических, акустооптических и нелинейных оптических устройствах [1], что определяет постоянный интерес к исследованиям их физических свойств.

Хорошо известно, что проведение восстановительных термохимических обработок позволяет резко увеличить электрическую проводимость кристаллов НЛ. Это уменышает влияние пироэлектрического эффекта на параметры модуляторов добротности твердотельных лазеров [2] и фильтров на ПАВ [3], изготовленных из $\mathrm{LiNbO}_{3}$, при изменении температуры окружающей среды. Наиболее эффективный (с точки зрения влияния на электрическую проводимость) восстановительный отжиг НЛ проводится либо в чистом водороде [4], либо в азотно-водородной смеси [3]. Однако и высокотемпературный отжиг НЛ в насыщенных парах воды при давлении 10-30 bar также оказывает сильное влияние на электрические свойства этого материала [5].

При отжиге кристаллов НЛ в вакууме или водороде образец теряет некоторое количество кислорода, что приводит к появлению кислородных вакансий и (в качестве компенсаторов заряда) биполяронов $\mathrm{Nb}_{\mathrm{Nb}}^{4+}-\mathrm{Nb}_{\mathrm{Li}}^{4+}$ [6]. В настоящее время имеются прямые подтверждения того, что и при отжиге НЛ в насыщенных парах $\mathrm{H}_{2} \mathrm{O}$ или $\mathrm{D}_{2} \mathrm{O}$ в образце происходят аналогичные процессы [7]. Было установлено, что температурная зависимость удельной электрической проводимости $\sigma(T)$ восстановленных кристаллов НЛ в диапазоне температур 290-380 К подчиняется закону Аррениуса: $\sigma(T)=\frac{D}{T} \exp \left(-\frac{E_{a}}{k_{0} T}\right)$, где $k_{0}-$ постоянная Больцмана,
$D$ - константа, пропорциональная объемной концентрации подвижных носителей заряда. Значение энергии активации $E_{a}$ лежит в диапазоне $0.68-0.70 \mathrm{eV}[7,8]$ и отвечает биполяронному характеру проводимости.

В процессе исследования электрической проводимости объемных кристаллов НЛ, восстановленных в атмосфере водорода [8] и в насыщенных парах воды [7], были обнаружены эффекты, свидетельствующие о нестабильности и деградации электрических свойств этих образцов после прогревов на воздухе до температур 423-473 К. Очевидно, такие явления ограничивают диапазон температур, в котором могут эксплуатироваться изделия на основе этого материала.

Целью настоящей работы является изучение влияния контролируемых дополнительных прогревов в сухом воздухе на электрические свойства кристаллов НЛ, предварительно прошедших восстановительную термохимическую обработку и выяснение причин возникновения этого явления.

\section{Образцы и методика проведения экспериментов}

Для проведения экспериментов использовались три номинально беспримесных кристалла НЛ конгруэнтного состава, прошедших восстановительную термохимическую обработку в насыщенных парах $\mathrm{H}_{2} \mathrm{O}$ и $\mathrm{D}_{2} \mathrm{O}$, a также два образца НЛ, восстановленных в чистом $\mathrm{H}_{2}$. Образцы помещались в кварцевые ампулы с добавлением $\mathrm{H}_{2} \mathrm{O}$ или $\mathrm{D}_{2} \mathrm{O}$, а масса воды рассчитывалась так, чтобы давление насыщенных водяных паров в ампулах при $773 \mathrm{~K}$ составляло $\sim 1$ bar. Ампулы замораживались при $263 \mathrm{~K}$, после чего быстро откачивались до давления $0.15 \mu$ bar и запаивались. Термообработка проводи- 
лась при $T_{a}=773 \mathrm{~K}$ в течение $5 \mathrm{~h}$. Отжиг в водороде также проводился в кварцевых ампулах, заполненных газом под давлением 0.5 bar при комнатной температуре, продолжительность термообработки составляла $1 \mathrm{~h}$ при $T_{a}=873 \mathrm{~K}$. Синтез кристаллов и их отжиги проводились на НПП „Карат“.

Дополнительную температурную обработку восстановленные образцы проходили на воздухе в малоинерционном нагревателе сопротивления с управлением от ПК. Был использован следующий алгоритм: квазилинейный рост температуры от комнатной до заданного значения $T_{0 x}$ в течение $15 \mathrm{~min}$; выдержка $4 \mathrm{~h}$ при заданной температуре; уменышение температуры до комнатной в процессе естественного охлаждения нагревателя. Максимальное отклонение температуры образца от заданной не превышало $4 \mathrm{~K}$ на всех стадиях прогрева.

Для электрофизических экспериментов использовалась универсальная установка, позволяющая проводить исследования электрического импеданса в диапазоне $10^{-3}-10^{5} \mathrm{~Hz}$ и выполнять прецизионные измерения проводимости на постоянном напряжении [9]. Методика проведения измерений при изменении температуры образца приведена в [10].

\section{Результаты эксперимента}

Прогрессирующую деградацию электрических свойств восстановленных кристаллов НЛ наглядно демонстрируют результаты исследования температурной зависимости модуля электрического адмиттанса образца $|Y|$, проведенные на частоте $0.1 \mathrm{~Hz}$. Измерения выполнялись на кристалле НЛ, восстановленном в атмосфере чистого $\mathrm{H}_{2}$ и проводились в режиме непрерывного увеличения температуры образца со скоростью $0.12-0.15 \mathrm{~K} / \mathrm{min}$. Электроды были нанесены

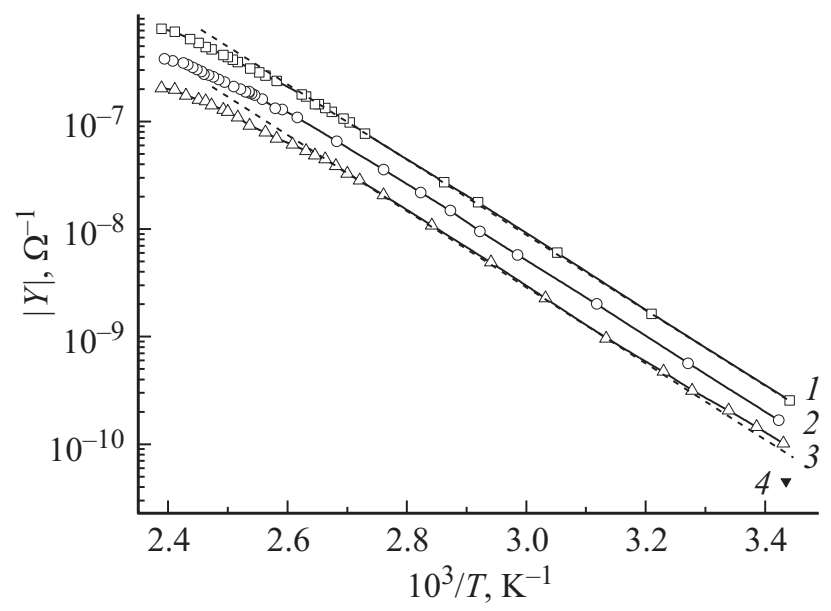

Рис. 1. Температурные зависимости модуля адмиттанса образца НЛ, восстановленного в $\mathrm{H}_{2}$ на частоте $0.1 \mathrm{~Hz}$, полученные в течение первого 1, второго 2 и третьего 3 циклов прогрева. 4 - значение активной проводимости образца $S$, измеренное после третьего цикла прогрева.

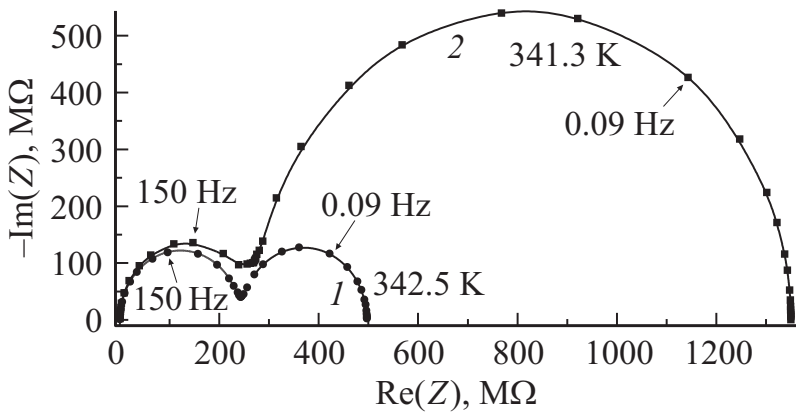

Рис. 2. Диаграммы Найквиста восстановленных образцов НЛ, прошедших прогрев при $T_{0 x}=423 \mathrm{~K} 1$ и $T_{0 x}=473 \mathrm{~K} 2$. Указана температура, при которой выполнялись эксперименты.

на полярные поверхности образца. Было проведено три последовательных цикла нагрева и результаты соответствующих измерений приводятся на рис. 1.

На этом же рисунке приведен результат измерения электрической проводимости образца по постоянному току $(S)$ после завершения третьего цикла прогрева - видно, что активное сопротивление образца при температуре $291 \mathrm{~K}$ увеличилось примерно в 6 раз по сравнению с исходным.

Данные, полученные в первом же цикле нагрева, свидетельствуют о том, что, начиная с температуры $\sim 380 \mathrm{~K}$, имеет место прогрессирующее отклонение температурной зависимости $|Y|$ от зависимости, соответствующей закону Аррениуса (штриховые линии на рис. 1). Эта тенденция повторяется и в последующих циклах прогрева, причем после охлаждения образца до комнатной температуры наблюдается уменьшение адмиттанса образца по сравнению со значением, исходным для данного цикла. При проведении третьего цикла прогрева отклонение зависимости $S(T)$ от закона Аррениуса наблюдается также и при температурах, близких к комнатной, однако причиной этого явления является чисто аппаратурный эффект - нарушение условия $|Y| \cong S[11]$.

Для исследований влияния дополнительного прогрева в сухом воздухе при $T_{0 x}=423 \mathrm{~K}$ и $T_{0 x}=473 \mathrm{~K}$ на электрические свойства восстановленных кристаллов также были проведены эксперименты по измерению импеданса двух кристаллов НЛ, прошедших термообработку в насыщенных парах $\mathrm{H}_{2} \mathrm{O}$. Предварительное исследование импеданса этих же образцов в диапазоне температур 295-350 К при нанесении электродов как на полярную, так и неполярные пары граней показало, что зависимость мнимой части импеданса образца $\operatorname{Im}(Z)$ от действительной $\operatorname{Re}(Z)$ (так называемая диаграмма Найквиста) близка к правильной полуокружности, а энергия активации удельной электрической проводимости отвечает установленной ранее [7].

Типичные диаграммы Найквиста этих образцов после дополнительных прогревов, полученные при близких температурах, приведены на рис. 2. Вид этих диа- 
грамм указывает на то, что эквивалентная электрическая схема кристалла может быть представлена в виде двух последовательно соединенных параллельных $R C$ цепочек $[8,12]$, одна из которых $\left(R_{1}\right.$ и $\left.C_{1}\right)$ отвечает за внутреннюю область кристалла и формирует высокочастотную часть диаграммы, а вторая $\left(R_{2}\right.$ и $\left.C_{2}\right)$ моделирует свойства приэлектродной области [8]. Наглядно видно, что с увеличением $T_{0 x}$ сопротивление приповерхностных слоев резко возрастает. Качественно подобные результаты были получены и при нанесении электродов на неполярные пары граней этих кристаллов.

Восстановительные отжиги в пределах ошибки не влияют на главные значения тензора диэлектрической проницаемости кристаллов НЛ в области низких частот (до $20 \mathrm{kHz}$ ) в исследуемом температурном диапазоне [8]. Поэтому в соответствии с эквивалентной схемой кристалла можно оценить суммарную толщину приповерхностных слоев с модифицированными электрическими свойствами $d_{m}$ :

$$
d_{m} \cong \frac{C_{1}}{C_{2}+C_{1}} d
$$

где $d-$ общая толщина кристалла, $C_{1}$ и $C_{2}-$ емкости, соответствующие внутренней и приповерхностной (с модифицированными электрическими свойствами) областям. Значения $C_{1}$ и $C_{2}$ (и соответственно $d_{m}$ ) определялись из анализа экспериментальных данных исследования импеданса при 5-6 значениях температуры кристалла в области температур $295-380 \mathrm{~K}$. В результате обработки результатов были получены следующие значения $d_{m}: 2.8 \pm 0.8 \mu \mathrm{m}$ и $11.4 \pm 2.6 \mu \mathrm{m}$ для образцов, прогретых при $T_{0 x}=423$ и $473 \mathrm{~K}$ соответственно.

Аналогичная серия экспериментов, выполненная на этих же образцах после химического стравливания электродов (In-Ga эвтектика) и повторного их нанесения, показала, что электрические свойства образцов не изменились. Однако после шлифовки всех поверхностей образца, восстановленного в $\mathrm{H}_{2} \mathrm{O}\left(T_{0 x}=473 \mathrm{~K}\right)$ на глубину порядка $8-10 \mu \mathrm{m}$, диаграмма Найквиста (рис. 3) приобрела вид, близкий к диаграмме электрически однородного кристалла.

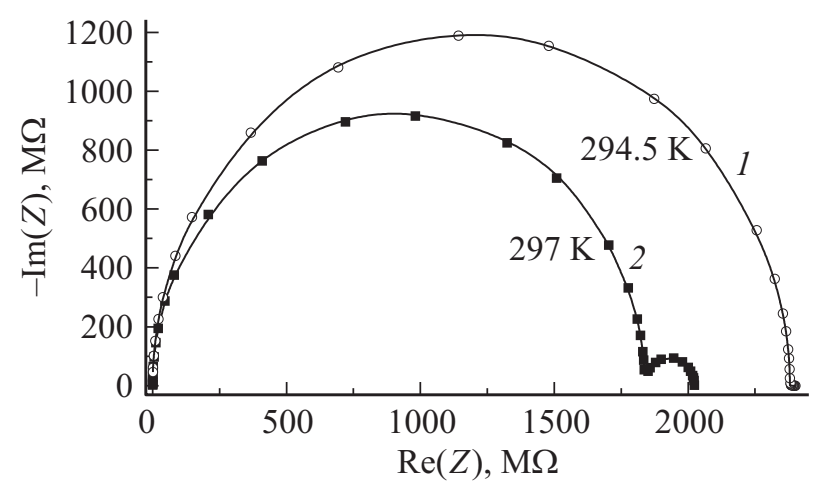

Рис. 3. Диаграммы Найквиста образца НЛ, восстановленного в $\mathrm{H}_{2} \mathrm{O}: 1$ - до проведения дополнительного прогрева, $2-$ после прогрева при $T_{0 x}=473 \mathrm{~K}$ и шлифовки поверхностных слоев на глубину порядка $10 \mu \mathrm{m}$.

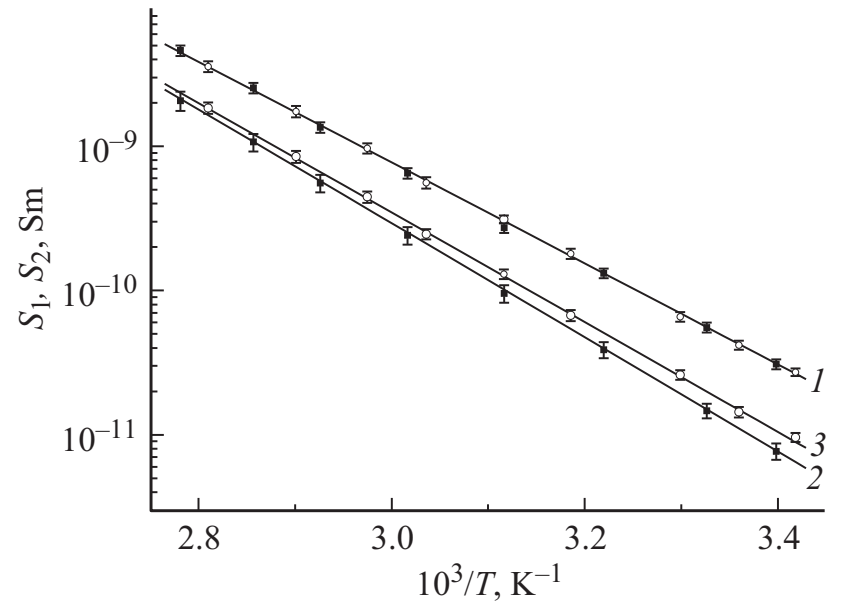

Рис. 4. Температурные зависимости электрической проводимости: 1 - объемной области кристалла $S_{1} ; 2$ и 3 - приповерхностных слоев $S_{2}$. Измерения, проведенные через 6 месяцев после прогрева представлены открытыми символами. Сплошные линии - результаты оптимального моделирования.

В ходе работы также было выполнено исследование электрических свойств образца НЛ, восстановленного в парах $\mathrm{D}_{2} \mathrm{O}$ и прогретого на воздухе до $T_{0 x}=473 \mathrm{~K}$. Результаты измерений, проведенных сразу после прогрева качественно и количественно очень близки к результатам, полученным для образца, восстановленного в парах $\mathrm{H}_{2} \mathrm{O}$. Однако повторные измерения, проведенные через 6 месяцев после прогрева, показало, что общее сопротивление образца уменьшилось. Температурные зависимости электрической проводимости объемной части образца $S_{1}=1 / R_{1}$ и приэлектродной области $S_{2}=1 / R_{2}$, полученные из результатов исследования импеданса, приводятся на рис. 4. Общее сопротивление кристалла $\left(R_{1}+R_{2}\right)$ совпадает с результатами измерений по постоянному току. Главным отличием результатов, полученных с полугодичным интервалом, является то, что эффективная энергия активации проводимости приповерхностных слоев $\left\langle E_{a}\right\rangle$ уменьшилась с $0.81 \pm 0.02$ до $0.78 \pm 0.02 \mathrm{eV}$. Оценочная суммарная толщина электрически модифицированных слоев $d_{m}$ в пределах ошибки при этом не изменилась и составляла $10.2 \pm 2.8$ тит.

\section{Обсуждение результатов}

Все виды примененных нами предварительных термохимических обработок кристаллов НЛ - отжиги в водороде, парах воды и тяжелой воды - носят восстановительный характер. За счет частичной потери образцом кислорода и образования биполяронов резко увеличиваются электрическая проводимость и оптическая плотность образца [3].

Вся совокупность экспериментов, описанных выше, подтверждает роль кислорода в изменениях электрофизических свойств НЛ. Мы полагаем, что во время 
проведения дополнительных прогревов восстановленных кристаллов НЛ в воздухе происходит диффузия кислорода из атмосферы в приповерхностную область образца, что сопровождается разрушением биполяронов $\mathrm{Nb}_{\mathrm{Nb}}^{4+}-\mathrm{Nb}_{\mathrm{Li}}^{4+}$ и резким уменьшением удельной электрической проводимости приповерхностных слоев.

После дополнительного прогрева в воздухе в образце возникает градиент концентрации вакансий кислорода (и соответственно биполяронов). При длительной выдержке такого образца при комнатной температуре должна происходить медленная внутренняя диффузия кислорода из приповерхностных областей кристалла в его объем, что приводит к сглаживанию концентрационного профиля биполяронов и соответственно к уменьшению общего сопротивления кристалла.

При помощи методики, основанной на анализе значения эффективной энергии активации $\left\langle E_{a}\right\rangle$, предложенной в [11], и использовании экспериментальных данных, представленных на рис. 4, можно в первом приближении оценить относительное изменение объемной концентрации биполяронов в приповерхностных слоях после длительной выдержки кристалла при комнатной температуре

Допустим, что темновая электрическая проводимость $\sigma_{d}(T)$ приповерхностных слоев образца определяется двумя типами носителей - протонами и биполяронами:

$$
\sigma_{d}(T)=\left[\frac{A}{T} \exp \left(-\frac{E_{1}}{k_{0} T}\right)+\frac{B}{T} \exp \left(-\frac{E_{2}}{k_{0} T}\right)\right]
$$

где $A$ и $B$ - параметры, пропорциональные объемной концентрации водорода $\left(n_{1}\right)$ и биполяронов $\left(n_{2}\right)$; $E_{1}=1.04 \mathrm{eV}$ - энергия активации протонной проводимости; $E_{2}=0.70 \mathrm{eV}$ - энергия активации биполяронной проводимости. Предположим, что после проведения восстановительного процесса значение $n_{1}$ и соответственно $A$ являются постоянными величинами, а $n_{2}$ и $B$ изменяются в процессе дополнительного прогрева и после него. Варьируя соотношение $K=A / B$ и относительную толщину электрически модифицированных слоев $N=d_{m} / d$, можно при помощи выражения (2) промоделировать зависимости $S_{1}(T)$ и $S_{2}(T)$. Результаты оптимального моделирования для области температур 293-360 К (сплошные линии) приводятся на рис. 4. Эти результаты получены при $N=700, K=1.8 \cdot 10^{-4}$ и $K=2.8 \cdot 10^{-4}$ для кривых 2 и 3 соответственно. Таким образом, изменение $\left\langle E_{a}\right\rangle$ от 0.81 до $0.78 \mathrm{eV}$ действительно может быть объяснено увеличением объемной концентрации биполяронов в приповерхностных областях за счет диффузии из объема кристалла. Значение $N$, полученное из данных измерения импеданса для этого образца, составляло $500 \pm 100$, что вполне разумно согласуется с результатом моделирования.

\section{Заключение}

Установлено, что при прогреве восстановленных кристаллов НЛ в сухом воздухе до температур, выше $380 \mathrm{~K}$ происходит заметное увеличение их электрического сопротивления, что связано с частичным заполнением кислородных вакансий и разрушением биполяронов в приповерхностных слоях кристалла. Этот эффект необходимо учитывать при эксплуатации изделий из восстановленного НЛ и, вероятно, восстановленного танталата лития [13].

Исходя из изложенного, можно сделать вывод о том, что диффузия кислорода в восстановленных кристаллах НЛ в области температур, близких к комнатной, гораздо более интенсивна, чем можно было бы предположить, основываясь на известных данных [14-17]. Исследованию процессов диффузии кислорода в восстановленных кристаллах НЛ при низких температурах будет посвящена отдельная работа.

Работа поддержана грантом РФФИ № 14-42-01557 и частично проектами Министерства образования и науки Украины ГБ/КМОН, ГБ/ЭМШ и М/120-2015.

\section{Список литературы}

[1] Arizmendi L. // Phys. Stat. Sol. A. 2004. Vol. 201. P. 253.

[2] Brickeen B., Shanta C. // Opt. Eng. 2010. Vol. 49. P. 124201.

[3] Bordui P., Jundt D., Standifer E., Norwood R., Sawin R., Galipeau J. // J. Appl. Phys. 1999. Vol. 85. P. 3766.

[4] Jösch W., Munser R., Ruppel W., Würfel P. // Ferroelectricity. 1978. Vol. 21. P. 623.

[5] Bollman W., Stöhr H.-J. // Phys. Stat. Sol. A. 1977. Vol. 39. P. 477.

[6] Volk T.R., Wöhlecke M. Lithium Niobate. Defects, photorefraction and ferroelectric switching. Berlin: SpringerVerlag, 2008. 250 p.

[7] Yatsenko A.V., Pritulenko A.S., Yevdokimov S.V., Sugak D.Yu., Syvorotka I.I., Sugak Yu.D., Solskii I.M., Vakiv M.M. // Sol. Stat. Phenom. 2015. Vol. 230. P. 233.

[8] Yatsenko A.V., Pritulenko A.S., Yevdokimov S.V., Sugak D.Yu., Solskii I.M. // Sol. Stat. Phenom. 2013. Vol. 200. P. 193.

[9] Евдокимов С.В., Притуленко А.С., Сапига А.А., Яценко A.B. // Ученые записки Таврического национального университета им. В.И. Вернадского. Серия „Физ.-мат.“. 2011. Т. 24(63). Вып. 1. С. 187.

[10] Яценко А.В., Палатников М.Н., Сидоров Н.В., Притуленко А.С., Евдокимов С.В. // ФТТ. 2015. Т. 57. Вып. 5. С. 932.

[11] Притуленко А.С., Яценко А.В., Евдокимов С.В. // Кристаллография. 2015. Т. 60. Вып. 2. С. 293.

[12] Impedance spectroscopy. Theory, experiment, and applications / Ed. by E. Barsoukov, J. Ross Macdonald. New Jersey, Hoboken: Wiley \& Sons Inc. 2005. 595 p.

[13] Yan T., Liu H., Wang J., Zheng F., Yao S., Xia Z., Wu J., Boughton R. // J. Alloy. Comp. 2010. Vol. 497. P. 412.

[14] Fielitz P., Schneider O., Borchardt G., Weidenfelder A., Fritze H., Shi J., Becker K.D., Ganschow S., Bertram R. // Sol. Stat Ionics 2011. Vol. 189. P. 1.

[15] Bredikhin S., Sharner S., Klinger M., Kveder V., Red'kin B., Weppner W. // J. Appl. Phys. 2000 Vol. 88. P. 5687.

[16] Mehta A., Chang E.K., Smyth D.M. // J. Mater. Res. 1991. Vol. 6. P. 851.

[17] Jorgensen P.J., Bartlett R.W. // J. Phys. Chem. Solids. 1969. Vol. 30. P. 2639. 